hurricane of 1987, and grey-squirrel damage (Mountford et al., 1999; Mountford and Peterken, 2003).

At broader spatial and temporal scales, the Holocene pollen sequence from Church Moor (Grant et al., 2009) and other localities in southern England indicate that beech was present as early as 6 cal ka BP, initially at extremely low abundance (1-2\%). Its expansion typically appears to be associated with anthropogenic activity in the late Holocene. In the High Weald area of southern Britain, south of London, beech expansion is also related to a change in land use, particularly to the adoption of the wood-pasture system (Waller and Schofield, 2006). Pannage (feeding by domestic pigs on acorns) may have particularly favored beech, as its seeds are highly dependent upon ground disturbance for establishment (Björkman, 1999; Watt, 1923).

\section{Future trends}

A combination of natural and humaninduced processes over the past several hundred years has led to the development of modern A\&O Woodlands as a New Forest landscape element. Figure 2 summarizes the drivers of past change, contemporary pressures and possible future for
A\&O Woodland. Sustaining the culturally generated structure and composition may require revival of the traditional management practices that formed the current landscape (or substitutes that achieve the same effect). The balance (or imbalance) between openness and regeneration reflects levels of grazing and browsing by stock and wild deer, and thus there is a role for stock and deer management. The current age structure already contributes to any future trajectory, and further opening of old stands within the present woodlands is inevitable. It will now be some time before a new generation of trees matures, irrespective of which management strategy is adopted. Furthermore, any longterm management intervention now also requires anticipation of climate-change pressures. For example, beech is susceptible to wind-throw, which will increase with projected greater storminess. Revival of pollarding on younger trees would mitigate wind-throw while also continuing a traditional past practice that underlies the structure and composition of contemporary $A \& O$ Woodland. On the other hand, projected levels of summer drought in the south of England may stress beech to an extent that it cannot thrive, in which case the woodland will follow a different tra- jectory and A\&O Woodlands as they are known today will eventually take on a new composition and appearance.

\section{Data}

More detailed accounts of the pollen data can be found in Grant and Edwards (2008) and Grant et al. (2009); the pollen data will be deposited with the European pollen database (www. europeanpollendatabase.net/) in due course and, until then, are available from M.J. Grant upon request.

\section{References}

Flower, N., 1980: The Management History and Structure of Unenclosed Woods in the New-Forest, Hampshire, Journal of Biogeography, 7: 311-328.

Grant, M.J. and Edwards, M.E., 2008: Conserving idealized landscapes: past history, public perception and future management in the New Forest (UK), Vegetation History and Archaeobotany, 17 551-562.

Mountford, E.P., Peterken, G.F., Edwards, P.J. and Manners, J.G., 1999: Long-term change in growth, mortality and regeneration of trees in Denny Wood, an old-growth wood-pasture in the New Forest (UK), Perspectives in Ecology, Evolution and Systematics, 2: 223-272.

Tubbs, C.R., 2001: The New Forest: History, Ecology and Conservation, New Forest Ninth Centenary Trust, 450pp.

Waller, M.P. and Schofield, J.E., 2006: Mid to late Holocene vegetation and land use history in the Weald of south-eastern England: multiple pollen profiles from the Rye area, Vegetation History and Archaeobotany, 16: 367-384

For full references please consult:

http://www.pages-igbp.org/products/newsletters/ref2011_2.pdf

\title{
Grazing activities and biodiversity history in the Pyrenees: New insights on high altitude ecosystems in the framework of a Human-Environment Observatory
}

\author{
Didier Galop ${ }^{1}$, T. Houet' ${ }^{1}$, F. Mazier ${ }^{1}$, G. Leroux ${ }^{2}$ and D. Rius ${ }^{1}$ \\ 'Laboratory GEODE UMR 5602 CNRS (GEOgraphie De I'Environnement), University of Toulouse, France; didier.galop@univ-tlse2.fr \\ ECOLAB UMR 5245 CNRS, University of Toulouse, France
}

\section{Reconstruction of the relationship between pastoral activities and vegetation history in the central Pyrenees demonstrates the importance of grazing pressure in the maintenance of floristic diversity in highland regions that have been abandoned.}

In the context of biodiversity management, as encouraged by the European Union Habitats Directives and by the implementation of national strategies, the preservation of traditional agro-pastoral farming activities (in particular extensive grazing), is a major issue acting to maintain or restore open land that is favorable to biodiversity. Here, we present a case from the Pyrenean Mountains, which is considered the most important mountainous massif in southern Europe due to its biodiversity and high levels of endemism. Since the mid $20^{\text {th }}$ century, agricultural activities in these mountains have signifi- cantly declined, often accompanied by a change in grazing practices. From a pastoral point of view, the current situation in the Pyrenees is complex. In the Eastern Pyrenees, grazing areas are being abandoned, which is resulting in an expansion of heathland and forest. Conversely, in the Central and Western Pyrenees, an intensification of grazing is observed. This intensification creates problems that are characteristic of overgrazed areas; soil erosion and the fragmentation of animal habitats by fences. European and national policies are attempting to face this situation, where over-grazing and abandonment co- exist, through support of conservation organizations, such as the Pyrenees national park, the regional natural parks, natural reserves, and nature charities, which participate in the local implementation of the networking program "Natura 2000" (Magda et al., 2001). The development of a comanagement structure, with involvement of local and governmental environmental managers, is encouraged in order to set up strategies reconciling biodiversity conservation with restoration or maintenance of agro-pastoral activities. Pastoral activities are considered essential for maintaining open land, preventing the expansion of 
invasive species, and forestalling secondary succession of forests following past anthropogenic activities. For the majority of cases, a return to extensive grazing activities is highly recommended. However, this suggestion is often based on present-day observations with a temporal record spanning no more than 10 years (Canals and Sebastià, 2000).

The potential of incorporating historical ecology and paleoecology in conservation biology is now recognized, including their applicability to biodiversity maintenance, conservation evaluation and changing disturbance regimes. Paleo-studies can provide guidelines for environmental managers (Swetnam et al., 1999; Valsecchi et al., 2010). The effects of long-term, human-induced disturbances (i.e., grazing pressure) on ecosystem dynamics and their biodiversity still need to be further investigated.

\section{A Human-Environment Observatory: Insights on future dynamics}

The UpperVicdessos Valley (Ariège, eastern Pyrenees) is representative of a common scenario in the Pyrenean massif where agro-pastoral activities have reached an extremely low level, now characterized only by extensive grazing. Successional processes involving encroachment of open land and overgrowth by trees are now occurring rapidly at all altitudes. Hill slopes have all been subjected to an overwhelming encroachment of fallow land (Betula, Fraxinus, Corylus) whereas altitude zones used for summer grazing are progressively colonized by heathland (principally Juniperus communis, Calluna vulgaris, Cytisus scoparius). After thousands of years of intense agro-silvo-pastoral activities (going back to the late Neolithic period, Galop and Jalut, 1994), a rapid decline in human activities linked to rural depopulation took place during the first half of the $20^{\text {th }}$ century.

The Vicdessos Valley is therefore a particularly interesting case study. Since 2009, a Human-Environment Observatory (http://w3.ohmpyr.univ-tlse2.fr/ presentation_ohm_pyr.php) headed by the laboratory GEODE was set up by the Institute of Ecology and Environment of the French National Center for Scientific Research (INEE-CNRS). It aims to monitor past and present evolutions of human-environment interactions in order to anticipate future dynamics and consequently to provide a scientific basis for understanding the functioning of social-ecological systems. This implies a close collaboration with local and governmental planners in charge of management and conservation of landscapes and ecosystems. The observatory is a multidisciplinary consortium bringing together scientists to work on integrated micro-regional research (Pyrenean Valley scale). It involves observations and measures of present dynamics (e.g., meteorological and climatic observations, experimental approaches, monitoring of plant and animal communities) and studies of past human activities over long-term timescales. The latter uses instrumental and documentary data sources, tree de- mography (dendrology), old maps, agricultural statistics, aerial photographs, and long-term sedimentary proxy data (e.g., sedimentology, biogeochemistry, pollen and charcoal) from lakes and bogs in the valley.

\section{From over-grazing to abandonment: 200 years of grazing activities}

In the Vicdessos Valley, the hanging valley of Bassiès (altitude between 1400 and $2500 \mathrm{~m}$ asl) lies one of the study sites of

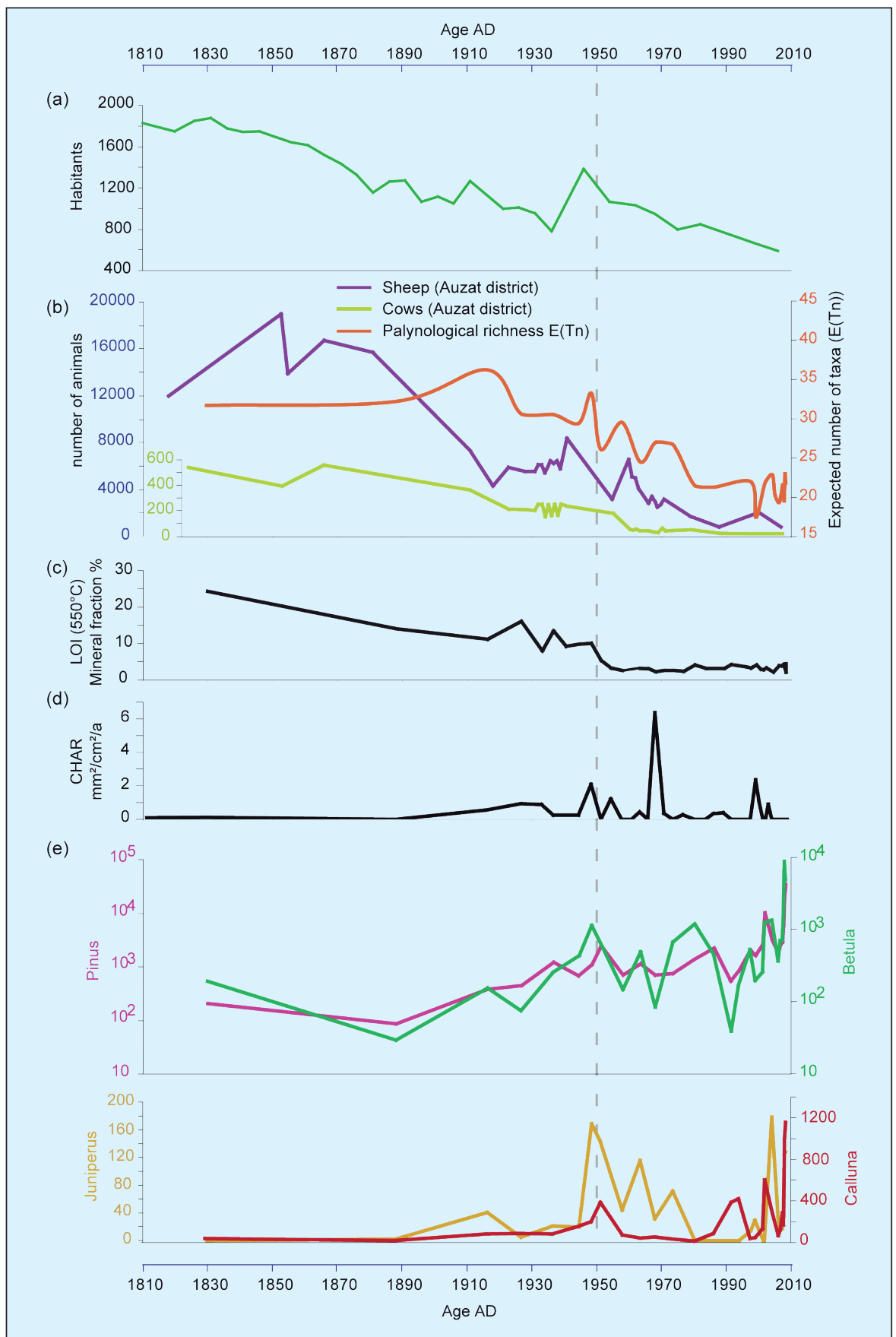

Figure 1: Trajectories of changes observed since the beginning of the $19^{\text {th }}$ century in the Bassiès Valley based on historical and paleodata. a) Evolution of the Auzat commune population; $\boldsymbol{b}$ ) Comparison between the evolution of grazing pressure recorded in agricultural statistics of the Auzat commune and the estimated palynological richness $(E(T n))$ inferred from pollen records from the Orry de Théo peat bog; $c$ ) Ash content (mineral fraction; $\mathrm{LOI} 550^{\circ} \mathrm{C}$ )

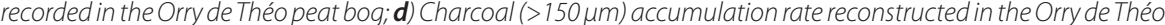
peat profile; e) Pollen accumulation rates $\left(\mathrm{g} \mathrm{cm}^{-2} a^{-1}\right)$ of selected taxa recorded in the Orry de Théo peat bog. This reconstruction shows, at a local scale, the change from a scenario of over-grazing to a near-total abandonment of summer pastoral farming activities. In the 1950s, an important period of transition is noted during which grazing pressure can no longer curb the development of heathland species and tree recolonization (dashed gray line). 
the observatory. The research focuses on the impact of grazing activities on highaltitude ecosystems. Paleoecological data, including pollen and charcoal (>150 $\mu \mathrm{m})$ accumulation rates and loss-on-ignition (LOI), have been retrieved from the small peat bog of Orry de Théo. This sequence illustrates the history of vegetation cover, ing activities over the last 200 years (Fig. 1). Rarefaction analysis was undertaken on pollen data to estimate the variations of palynological richness assumed to reflect the floristic diversity, and vegetation and landscape dynamics over time (Berglund et al., 2008). The comparison of the palynological richness with documentary sources (demographic data and book records of number of cattle in the valley) provides valuable insights on the role of human-induced disturbances such as grazing activities on floristic and landscape diversity. Figure 1 shows a positive association between grazing pressure and floristic richness. This correlation remains soil erosion and fire in relation to graz-

high until around the 1920s despite a decrease in sheep numbers, whereas the presence of cattle leads to soil degradation. A threshold is reached in the 1950s: the decline of flocks associated with a modification of pastoral practices leads to under-grazing and limits the soil erosion. At the same time, the overgrowing of Juniper and Calluna heathlands and the expansion of trees (Pinus and Betula), no longer controlled by browsing, are favored. Fire signatures recorded between 1950 and 1970 may indicate the use of fire by the shepherds to restore and clear their pastures. From the beginning of the 1980s, a significant reduction in the number of farmers in the valley has progressively led to a near-total disappearance of grazing activity. In these previously grazed areas, an inevitable and probably irreversible (except through expensive restoration actions) return to forest has led to a decline in floristic diversity. Landscape dynamics are illustrated by reconstructions based on aerial photographs taken between

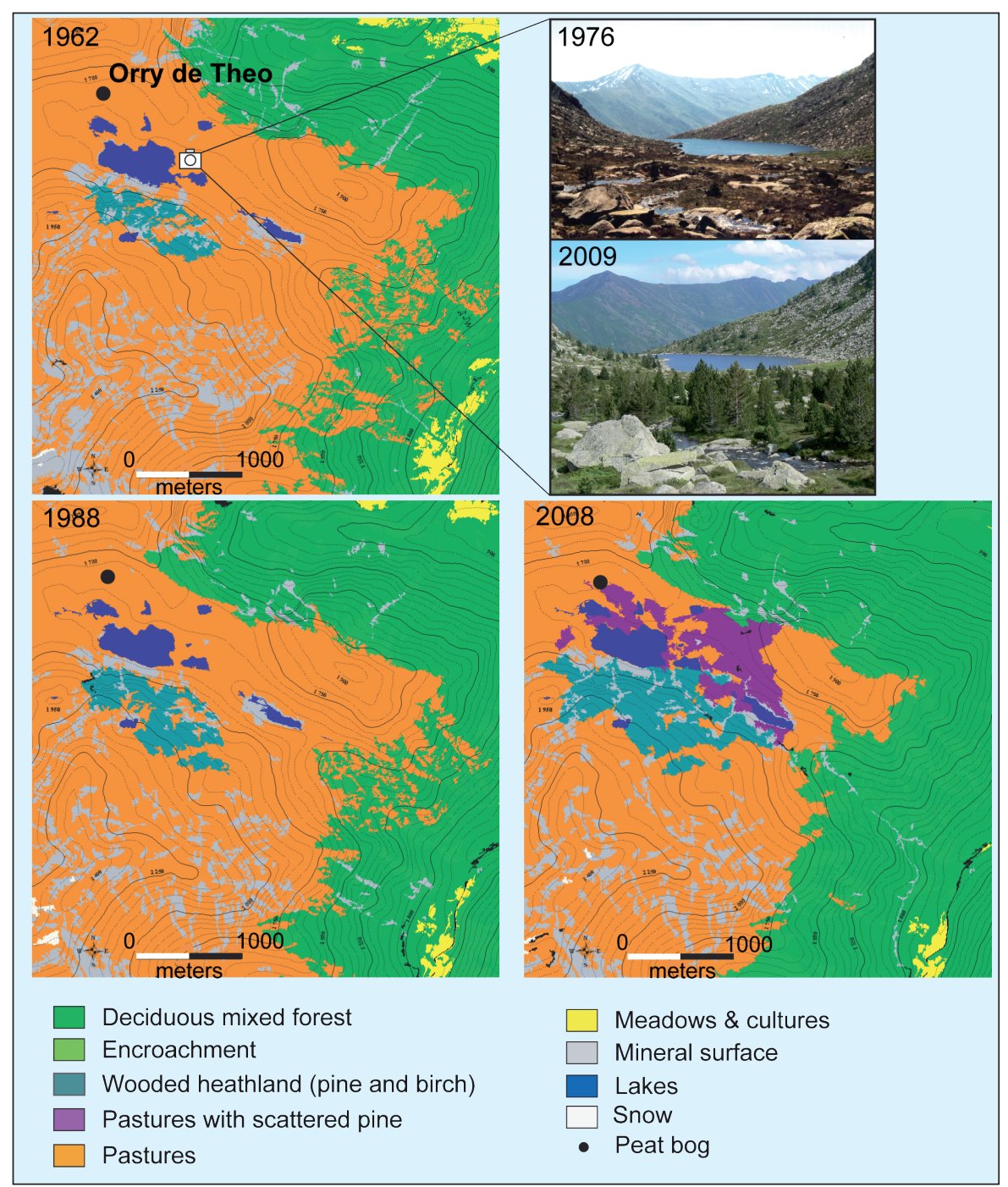

Figure 2: Maps based on aerial photographs (French National Geographic Institute) showing vegetation and land-use changes in the Bassiès Valley between 1962 and 2008. The grazing decline (orange area) is concomitant with increasing forest density, principally dominated by an expansion of Pinus uncinata and birch (aqua and purple areas). This density increase has been particularly rapid during the last 20 years as shown by the repeat photographs taken in the valley's pastoral zones between 1976 and 2009.
1962 and 2008 as well as repeat photographs showing the progression of pinedominated forest between 1976 and 2009 (Fig. 2). The correspondence between paleoecological data and documentary sources confirms the complementarity of the approaches.

The local case study of the Bassiès Valley gives information on diversity baselines, thresholds, and the resilience of mountainous ecosystems to anthropogenic disturbances. This study is also rich in lessons on the loss of floristic diversity related to the variability or the decline in grazing activities and to pine-dominated secondary succession in a context of under-grazing. This kind of integration of data is already being used by managers to affirm the necessity or futility of restoration actions, and especially to avoid thresholds and to reverse the trajectories of key processes.

\section{References}

Berglund, B.E., Gaillard, M.-J., Björkman, L. and Persson, T., 2008: Longterm changes in floristic diversity in southern Sweden: palynological richness, vegetation dynamics and land-use, Vegetation History and Archaeobotany, 17: 573-583

Canals, R.-M. and Sebastià, M.-T., 2000: Analyzing mechanisms regulating diversity in rangelands through comparative studies: a case in the southwestern Pyrenees, Biodiversity and Conservation, 9 965-984.

Galop, D. and Jalut, G., 1994: Differential human impact and vegetation history in two adjacent Pyrenean valleys in the Ariège basin, southern France, from $3000 \mathrm{BP}$ to the present, Vegetation History and Archeobotany, 4: 225-244.

Swetnam, T.W., Allen, C.D. and Betancour, J.L., 1999: Applied historical ecology: using the past to manage the future, Ecological applications, 9(4): 1189-1206.

Valsecchi, V., Carraro, G., Conedera, M. and Tinner, W., 2010: Late-Holocene vegetation and land-use dynamics in the southern Alps (Switzerland) as a basis for nature protection and forest management, The Holocene, 20(4): 483-495.

For full references please consult:

http://www.pages-igbp.org/products/newsletters/ref2011_2.pdf 